\title{
Can a patient with pulmonary hypertension travel safely by plane?
}

\author{
Berkay Ekici ®
}

Department of Cardiology and Aeromedical Centre, Faculty of Medicine, Ufuk University; Ankara-Turkey

\section{ABSTRACT}

Air travel is known as the safest way of transportation. Therefore, patients with health problems prefer to travel by air; however, those with heart or lung issues, who do not have any problems under normal conditions, may experience some problems in high altitude and different environmental conditions. In this review, we have described the points to be considered during air travel in patients with pulmonary hypertension.

Keywords: pulmonary hypertension, air travel, flight safety

\section{Introduction}

Airline transportation, which is the fastest and safest form of travel, is preferred frequently nowadays with the advancement of technology. Over a billion people worldwide travel on commercial aircrafts every year, and there are a reported 0.31 inflight deaths per million passengers carried. Cardiovascular events represent the main cause of death during a flight. Owing to engineering and financial constraints, the pressure inside the cabin is kept at a maximum altitude of $2,438 \mathrm{~m}$. This reduction in cabin pressure is equivalent to $15 \%$ breathable oxygen compared with $21 \%$ at sea level $(1,2)$.

In patients with a diagnosis of pulmonary hypertension $(\mathrm{PH})$, the hypobaric environment during air travel leads to a general hypoxic vasoconstriction in the pulmonary circulation, which exacerbates pulmonary vascular resistance and right ventricular afterload and may lead to acute right-heart failure. Therefore, in addition to the typical flight-related risks, such as deep vein thrombosis, pulmonary thromboembolism, and changes in fluid balance, people with cardiovascular and pulmonary diseases also have an increased risk of worsening hemodynamics during a flight (3).

Air travel can cause significant respiratory problems in a patient with severe pulmonary arterial hypertension (PAH) because of high-altitude hypoxemia. Despite the risks of physiological compromise, there are limited data on the effects of air travel in patients with PAH in the literature. It is known that air travel activates certain elements of human response to hypoxia, including increased ventilation and erythropoietin secretion (4). Another classic response, hypoxic pulmonary vasoconstriction, may be more clinically relevant. Therefore, hypoxia can cause increased pulmonary artery pressure that may lead to $\mathrm{PH}$ and ultimately right heart failure, such as in hypoxic lung disease and at high altitude. Such an effect may be important for some sensitive passengers. Hypoxic pulmonary vasoreactivity varies greatly among individuals, and high reactivity could lead to hypoxia-related diseases such as high-altitude pulmonary edema. Susceptible passengers may similarly be at risk of hypoxia-induced $\mathrm{PH}$ and its sequelae during a flight $(5,6)$.

Hypoxemia is common among patients with $\mathrm{PAH}$ traveling by air. Hypoxemia is mostly associated with ambulation during flight, lower cabin pressures, failure to use $\mathrm{O}_{2}$ in people with home oxygen (predominantly nighttime-only users), and longer flight duration. Patients with PAH traveling on long-duration flights or who have a history of oxygen supply should be evaluated for supplemental in-flight oxygen (7).

There are no studies using flight simulation to determine the need for oxygen supply during prolonged air travel in patients with PAH. The European Society of Cardiology and the European Respiratory Society (ERS) (2015) guidelines recommend that oxygen supplementation should be considered in patients with World Health Organization functional class III and IV and arterial blood $\mathrm{O}_{2}$ pressure continuously $<8 \mathrm{kPa}(60 \mathrm{~mm} \mathrm{Hg})$. Oxygen support inspired by $2 \mathrm{~L} / \mathrm{min}$ increases partial pressure of oxygen

Address for Correspondence: Dr. Berkay Ekici, Department of Cardiology and Aeromedical Centre, 
to values seen at sea level. Similarly, these patients should avoid going to altitudes higher than $1,500-2,000 \mathrm{~m}$ without additional oxygen support. The patients should be warned to travel with written information about their PAH and to get in close contact with the local PH clinics (8). Guidelines for PH by the American College of Cardiology/American Heart Association suggest that supplemental oxygen be made available on commercial aircraft for patients with a pre-flight pulse oximetry oxygen saturation $<92 \%(9)$. For patients with chronic pulmonary disease who are planning to travel by air, ERS advises a minimum pulmonary vital capacity of $3 \mathrm{~L}$, a forced expiratory volume in 1 second $\left(\mathrm{FEV}_{1}\right)$ $>70 \%$ of reference, a minimum oxygen saturation of $85 \%$, and a minimum arterial partial oxygen pressure of $70 \mathrm{~mm} \mathrm{Hg}$, as well as a stable state of vital signs $(3,10)$.

The hypoxia altitude simulation test (HAST) is a standardized and well-known pre-flight assessment tool that has increasingly been used in patients with chronic obstructive pulmonary disease recently. The patient breathes a mixture of hypoxic gases of $15.1 \%$ oxygen, mimicking the effects of an altitude of 8,000 feet $(2,438 \mathrm{~m})$, and changes in oxygen saturation and arterial blood gases are used to estimate the severity of hypoxemia during flight. The patient is also monitored for symptoms and myocardial ischemia or arrhythmias, and the overall goal is to reduce morbidity and mortality during a flight. The pre-flight aeromedical assessment of patients with sensitive respiratory systems can be performed by combining echocardiography with a standard HAST, by inhaling the mild hypoxic gas mixture, and predicting responses during flight. At sea level, this gas mixture replicates the in-flight partial inspired oxygen pressure of at the maximum allowed altitude of 8,000 feet. HAST-echo can lead to predicting in-flight changes of pulmonary hemodynamics, prescribing in-flight complementary oxygen, and ultimately deciding on suitability for flight $(11,12)$.

Employment as aircraft crew or cabin crew may not be safe for people who are prone to flight-induced $\mathrm{PH}$, even in the absence of symptoms. Patients in whom exaggerated hypoxic pulmonary vasoreactivity can be predicted, such as those diagnosed with Chuvash polycythemia or with a history of high-altitude pulmonary edema, pre-employment screening with HASTecho may be recommended (13).

\section{Conclusion}

Considering the potential health risks of air travel in patients with $\mathrm{PH}$, all patients with $\mathrm{PH}$ should consult their physician prior to flying. Patients with sensitive respiratory systems should be warned by their physicians in terms of the risks that may occur during the flight and the necessary precautions to be taken before air travel. Large-scale studies are needed for more information on this issue.

Conflict of interest: None declared.

\section{References}

1. Cummins R0, Chapman PJ, Chamberlain DA, Schubach JA, Litwin PE. In-flight deaths during commercial air travel: How big is the problem? JAMA 1988; 259: 1983-8. [Crossref]

2. Mohr LC. Hypoxia during air travel in adults with pulmonary disease. Am J Med Sci 2008; 335: 71-9. [Crossref]

3. Thamm M, Voswinckel R, Tiede H, Lendeckel F, Grimminger F, Seeger W, et al. Air travel can be safe and well tolerated in patients with clinically stable pulmonary hypertension. Pulm Circ 2011; 1: 239-43. [Crossref]

4. Haase VH. Regulation of erythropoiesis by hypoxia-inducible factors. Blood Rev 2013; 27: 41-53. [Crossref]

5. Hussain A, Suleiman MS, George SJ, Loubani M, Morice A. Hypoxic Pulmonary Vasoconstriction in Humans: Tale or Myth. Open Cardiovasc Med J 2017; 11: 1-13. [Crossref]

6. Fuehrer J, Huecker MR. High Altitude Cardiopulmonary Diseases. [Updated 2020 0ct 15]. In: StatPearls [Internet]. Treasure Island (FL): StatPearls Publishing; 2021.

7. Roubinian N, Elliott CG, Barnett CF, Blanc PD, Chen J, De Marco T, et al. Effects of commercial air travel on patients with pulmonary hypertension air travel and pulmonary hypertension. Chest 2012; 142: 885-92. [Crossref]

8. Galiè N, Humbert M, Vachiery JL, Gibbs S, Lang I, Torbicki A, et al. 2015 ESC/ERS Guidelines for the diagnosis and treatment of pulmonary hypertension: The Joint Task Force for the Diagnosis and Treatment of Pulmonary Hypertension of the European Society of Cardiology (ESC) and the European Respiratory Society (ERS): Endorsed by: Association for European Paediatric and Congenital Cardiology (AEPC), International Society for Heart and Lung Transplantation (ISHLT). Eur Respir J 2015; 46: 903-75. [Crossref]

9. McLaughlin VV, Archer SL, Badesch DB, Barst RJ, Farber HW, Lindner JR, et al.; American College of Cardiology Foundation Task Force on Expert Consensus Documents; American Heart Association; American College of Chest Physicians; American Thoracic Society, Inc; Pulmonary Hypertension Association. ACCF/ AHA 2009 expert consensus document on pulmonary hypertension a report of the American College of Cardiology Foundation Task Force on Expert Consensus Documents and the American Heart Association developed in collaboration with the American College of Chest Physicians; American Thoracic Society, Inc.; and the Pulmonary Hypertension Association. J Am Coll Cardiol 2009; 53 : 1573-619.

10. Fischer R, Nowak D, Huber RM. Fitness to fly of patients with lung disease. Dtsch Med Wochenschr 2001; 126: 1115-7. [Crossref]

11. Mohr LC. The hypoxia altitude simulation test: an increasingly performed test for the evaluation of patients prior to air travel. Chest 2008; 133: 839-42. [Crossref]

12. Dine CJ, Kreider ME. Hypoxia altitude simulation test. Chest 2008; 133: 1002-5. [Crossref]

13. Smith TG, Talbot NP, Chang RW, Wilkinson E, Nickol AH, Newman DG, et al. Pulmonary Artery Pressure Increases During Commercial Air Travel in Healthy Passengers. Aviat Space Environ Med 2012; 83: 673-6. [Crossref] 